\title{
Percepção do conforto térmico no Semiárido pernambucano: estudo piloto nos municípios de Petrolina e Serra Talhada
}

A urbanização de municípios do Semiárido brasileiro pode gerar efeitos negativos na qualidade ambiental e térmica, caso não haja um planejamento desse territórios. O presente estudo se propõe a analisar, de modo preliminar, a percepção da população em relação ao conforto térmico em duas cidades do Semiárido pernambucano: Serra Talhada e Petrolina. Para obter dados referentes à percepção aplicou-se um questionário pré-estruturado com base na ISO 10.551, por meio de plataforma online para os moradores dos respectivos municípios interessados em participar durante dos dias 11,12 e 13 de dezembro do ano de 2016 . Para avaliação do conforto térmico empregou-se o índice bioclimático proposto por Thom. Foram obtidas 19 respostas válidas em Petrolina, e 21 em Serra Talhada. A maioria dos participantes foi do sexo feminino com idade entre 21 e 30 anos, com conhecimento do conceito de conforto térmico. Os resultados indicam que em Petrolina o número de moradores com percepção do desconforto térmico é maior quando comparado ao município de Serra Talhada. Entretanto os resultados da análise de conforto térmico em Serra Talhada apontam para um crescente desconforto na maioria dos dias de análise.

Palavras-chave: Stress térmico; Qualidade ambiental; Planejamento urbano.

\section{Perception of thermal comfort in the Semiarid region of Pernambuco: a study in the cities Petrolina and Serra Talhada}

The urbanization of municipalities in the Brazilian semi-arid region can have negative effects on environmental and thermal quality, if there is no planning for these territories. The present study proposes to preliminary analysis the population's perception of thermal comfort in two cities in the semiarid region of Pernambuco: Serra Talhada and Petrolina. To obtain data related to perception, a pre-structured questionnaire was applied based on ISO 10,551, through an online platform for residents of the respective municipalities interested in participating during December 11, 12, 13 and 2016. For thermal comfort evaluation, the bioclimatic index proposed by Thom was used. 19 valid answers were obtained in Petrolina and 21 in Serra Talhada. Most of the participants were female aged between 21 and 30 years old, with knowledge of the concept of thermal comfort. The results indicate that in Petrolina the number of residents with perceived thermal discomfort is higher when compared to the municipality of Serra Talhada. However, the results of the thermal comfort analysis in Serra Talha point to an increasing discomfort on most days of analysis.

Keywords: Thermal stress; Environmental Quality; Urban planning.

Topic: Planejamento Urbano

Reviewed anonymously in the process of blind peer
Received: 02/12/2020

Approved: $24 / 12 / 2020$
Symone Maria Pancracio Falcão (iD)

Universidade Federal Rural de Pernambuco, Brasil http://lattes.cnpq.br/2647767989447545

http://orcid.org/0000-0003-0216-7894

monempf@gmail.com

Ana Paula Xavier de Gondra Bezerra

Universidade Federal de Pernambuco, Brasil

http://orcid.org/0000-0003-4669-9673

http://lattes.cnpq.br/1784609374320343

anapaula.gondra@gmail.com

Fabricio Ângelo Gabriel (iD)

Universidade Federal do Espírito Santo, Brasil

http://lattes.cnpq.br/4141277873952734

http://orcid.org/0000-0002-6367-6740

fabricio.gabriel@outlook.com
Romildo Morant de Holanda (iD)

Universidade Federal Rural de Pernambuco, Brasil

http://lattes.cnpq.br/4283130448063981

http://orcid.org/0000-0001-7945-3616

romildomorant@gmail.com
Referencing this:

FALCÃO, S. M. P.; GONDRA, A. P. X.; GABRIEL, F. A.; HOLANDA, R. M. Percepção do conforto térmico no Semiárido pernambucano: Estudo piloto nos municípios de Petrolina e Serra Talhada. Revista Ibero Americana de Ciências Ambientais, v.11, n.7, p.775-786, 2020. DOI: http://doi.org/10.6008/CBPC2179-6858.2020.007.0059 


\section{INTRODUÇÃO}

A região do semiárido no Brasil se estende por área de 10 estados, ocupando cerca de 10,2\% do território nacional (SUDENE, 2017). A sobreposição dos eventos de estiagem devido a um severo déficit hídrico, implica num enfretamento constante dessa região às ameaças da sua segurança alimentar, hídrica e socioeconômica (MARENGO et al., 2016).

O semiárido é afetado pela desertificação devido à sua predisposição geológica, entretanto, esse processo tem sido intensificado devido às mudanças climáticas, de modo a causar danos à sustentabilidade de seus ecossistemas (TAVARES et al., 2019). Atrelado a tais condições climáticas adversas, tem-se a crescente e desordenada urbanização nessa região, em razão do aumento de áreas impermeabilizadas, redução de áreas verdes, e verticalização de edificações (BEZERRA et al., 2013). Dentre os efeitos negativos advindos da urbanização destacam-se, o desconforto térmico humano (SHARIFI et al., 2018), aumento do consumo de energia elétrica durante o verão (ZHOU et al., 2012), e danos à qualidade do ar e água (LEAL FILHO et al., 2018).

Estudos de destaque já demonstram a queda na qualidade de vida das populações associada à degradação ambiental, acarretada por políticas desenvolvimentistas e ausência de conscientização humana face ao uso dos recursos naturais (BRASILEIRO, 2009). Diante disso, pesquisas estão sendo empregadas de modo a sugerir um planejamento sustentável do espaço urbano que leve em consideração a percepção da população (MARTINI et al., 2014).

Gomes et al. (2019), em estudo sobre clima urbano e percepção térmica, destacam que as alterações antrópicas no espaço urbano associadas ao desconforto térmico nas cidades do semiárido carecem de investigação e debate para subsidiar seu planejamento urbano.

A percepção ambiental é um modo de compreender a relação sociedade-natureza diante das mudanças ambientais, e como os indivíduos constroem conceitos e valores nessa relação (OLIVEIRA et al., 2011). Portanto, análises de percepção são fundamentais para implementação das práticas de Educação Ambiental, de modo a inteirar a sociedade para mudanças de comportamento e construção de valores que contribuam com sustentabilidade (PINHEIRO et al., 2011).

A Educação Ambiental pautada na percepção das variações climáticas e sua influência na saúde e execução de atividades humanas, como o convívio social, agricultura, o uso de matrizes energéticas, pode ser uma aliada no processo de sensibilização ambiental. Desse modo, é importante empregar essa prática para planejamento e ordenamento territorial dos municípios do Semiárido, no qual vivem cerca de 39 milhões de pessoas vivendo em áreas urbanas (OJIMA, 2013).

Nesse sentido, o objetivo do presente trabalho foi realizar um estudo piloto a partir de uma análise preliminar acerca da percepção da população em relação ao conforto térmico, com o emprego de índice bioclimático, nas cidades de Petrolina e Serra Talhada no Semiárido pernambucano. 


\section{METODOLOGIA}

\section{Área de Estudo}

O Semiárido abrange $853.383,59 \mathrm{~km}^{2}$ do território brasileiro, se distribui dentre 1.262 municípios pertencentes aos estados do Maranhão, Piauí, Ceará, Rio Grande do Norte, Paraíba, Pernambuco, Alagoas, Sergipe Bahia e Minas Gerais. Os critérios que delimitam essa região adotados pela Superintendência de Desenvolvimento do Nordeste - SUDENE são; Precipitação igual ou superior aos 800 mm/ano; Índice de Aridez de Thornthwaite igual ou inferior a 0,50; Percentual diário de déficit hídrico igual ou superior a $60 \%$, considerando todos os dias do ano (SUDENE, 2017; INSA, 2017).

O município de Petrolina se localiza no Semiárido pernambucano (Figura 1), inserido na mesorregião do Sertão do São Francisco e na microrregião Petrolina do Estado de Pernambuco, possuindo limites ao norte com Dormentes, a sul com Estado da Bahia, a leste com Lagoa Grande, e a oeste com Estado da Bahia e Afrânio (CPRM, 2005a). Possui grande área territorial com, aproximadamente, em $4.561,872 \mathrm{~km}^{2}$ (CASTRO et al., 2015).

O clima de Petrolina apresenta longo período de estiagem, com duração de dois ou mais anos, ou podendo ter excesso de chuvas em anos diferentes (INSA, 2011). O município apresenta baixa precipitação média anual (435 mm) e taxa de 1520,9 mm evapotranspiração potencial (JATOBÁ et al., 2017). A estiagem é proveniente de interação de diversos fatores, podendo ser externos à região, como no caso da circulação dos ventos e correntes marinhas, que dependendo do movimento atmosférico impede a formação de nuvens de chuvas, ou intrínsecos, como topografia e a vegetação pouco robusta que implicam numa reflexidade alta do solo (MEDEIROS et al., 2015).

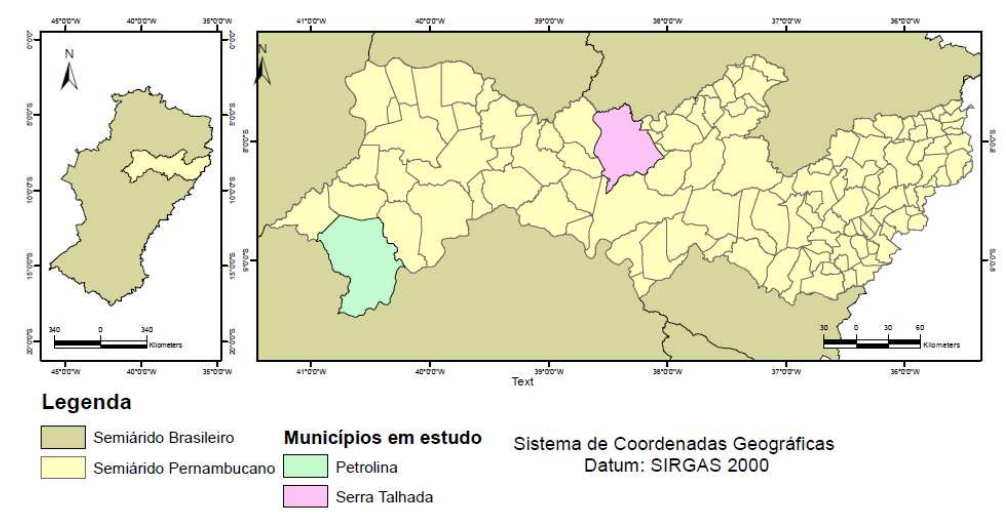

Figura 1: Semiárido Pernambucano: municípios de Petrolina e Serra Talhada.

O município de Serra Talhada, também localizado no Semiárido pernambucano (Figura 1), na parte setentrional da microrregião do Pajeú, porção Norte do Estado de Pernambuco, faz limites ao Norte, com o Estado da Paraíba, ao Sul, com a cidade de Floresta, a leste com Calumbi, Betânia e Santa Cruz da Baixa Verde e, a oeste, com São José do Belmonte e Mirandiba (CPRM, 2005b). O município fica aproximadamente a 418 km da capital, Recife, com altitude de $500 \mathrm{~m}$, apresentando temperatura média anual de 37 드, com precipitação variando de 450-750 mm entre março e maio (SILVA et al., 2009). A vegetação é formada, basicamente, por caatinga hiperxerófita com trechos de floresta caducifólia (CPRM, 2005b), apresentando estrato arbóreo arbustivo e herbáceo (árvores de até $12 \mathrm{~m}$ ) bastante desenvolvidos (SILVA et al., 2009). 
A cidade de Serra Talhada, assim como Petrolina, está inserida na unidade geoambiental da Depressão Sertaneja, apresentando paisagem típica do semiárido nordestino, caracterizada por superfície de pediplanação bastante monótona, com relevo suave-ondulado, basicamente (FARIAS, 2014).

\section{Percepção do conforto térmico}

Para coleta de dados primários acerca da percepção térmica, realizou-se o emprego de questionário préestruturado como principal instrumento de pesquisa (GIL, 2008). O período da coleta compreendeu os dias 11,12 e 13 do mês dezembro de 2016. A estruturação do questionário seguiu a ordem de 15 perguntas, considerando fatores subjetivos propostos pela normal ISO 10.551 (ISO, 1995). Para sua respectiva distribuição e aplicação, utilizou-se a plataforma 'Formulários do Google'. O público alvo consistiu em moradores das áreas urbanas dos municípios em estudo (Petrolina e Serra Talhada), que aceitaram participar da pesquisa e autorizaram o seu uso para fins de pesquisa científica.

Variáveis como cidade onde reside, sexo, altura, peso e idade serviram de parâmetro de representatividade da população e perfil do público. O questionário abordou; o conhecimento do conceito de conforto térmico; apoio às práticas de Educação ambiental com foco para qualidade térmica ambiental; percepção momentânea da sensação térmica; a percepção momentânea do conforto térmico, satisfação com a sensação térmica; alternativas empregadas para melhoria do conforto térmico individual. Após o encerramento do período da coleta, foi realizada compilação e análise dos dados obtidos através de planilhas informatizadas.

\section{Análise de conforto térmico}

Para análise comparativa com os dados de percepção do conforto térmico utilizou-se o índice bioclimático proposto por Thom (1959). O Índice de Thom (IDT) tem a finalidade de expressar o grau de sensação térmica que um indivíduo experimenta em condições ao ar livre. Para sua obtenção é feito o emprego de parâmetros meteorológicos, conforme equação:

$$
\text { IDT }=\mathrm{T}-(0,55-0,0055 \times \mathrm{UR}) \times(\mathrm{T}-14,5)
$$

Onde: IDT é o grau de desconforto térmico; Té a temperatura do ar (으); UR é a umidade relativa do ar (\%).

Tabela 1: Classificação do índice de desconforto de Thom (IDT), 1990.

\begin{tabular}{ll}
\hline DESCRIÇÃo & $\begin{array}{l}\text { CLASSES } \\
\text { (IDT) }\end{array}$ \\
\hline Bem-estar & DESCONFORTO \\
Menos de 50\% da população possui um ligeiro desconforto & $21<21$ \\
Outros 50\% da população possui um crescente desconforto. & $24 \leq 24$ \\
A maioria da população possui um relativo desconforto e há significativa deterioração da & $27 \leq$ IDT $\geq 29$ \\
condição psicofísica & $29 \leq$ IDT $\geq 32$ \\
Todos possuem um forte desconforto. & IDT $\geq 32$ \\
Estado de emergência médica, um desconforto muito forte. & \\
\hline
\end{tabular}

Os parâmetros de temperatura média do ar e umidade relativa média dos municípios de Petrolina e Serra Talhada foram coletados por meio da plataforma do Instituto Nacional de Meteorologia (INMET). Os dados extraídos da plataforma corresponderam aos dias da pesquisa (11, 12 e 13 de dezembro de 2016). Após 
elaboração dos índices para cada turno (manhã, tarde e noite) nos dias correspondentes, empregou-se a respectiva classificação da sensação térmica (Tabela 1).

\section{RESULTADOS E DISCUSSÃO}

Ao todo, 40 moradores dos municípios de Serra Talhada e Petrolina participaram da presente pesquisa, preenchendo totalmente os questionários enviados. A tabela 2 apresenta os dados obtidos acerca do perfil dos participantes.

Tabela 2: Perfil dos participantes de pesquisa de percepção de conforto térmico no Semiárido Pernambucano, 2016.

\begin{tabular}{|c|c|c|c|}
\hline \multirow{2}{*}{ Perfil do Público } & & \multicolumn{2}{|l|}{ Cidades } \\
\hline & & Petrolina & Serra Talhada \\
\hline \multirow{2}{*}{ Gênero } & Masculino & $42 \%$ & $24 \%$ \\
\hline & Feminino & $58 \%$ & $76 \%$ \\
\hline \multirow{5}{*}{ Faixa Etária } & $15-20$ & $*$ & $10 \%$ \\
\hline & $21-30$ & $32 \%$ & $80 \%$ \\
\hline & $31-40$ & $26 \%$ & $*$ \\
\hline & $41-50$ & $26 \%$ & $10 \%$ \\
\hline & Acima de 50 & $16 \%$ & $*$ \\
\hline \multirow{5}{*}{ Altura } & $1,00-1,30$ & $5 \%$ & $5 \%$ \\
\hline & $1,50-1,60$ & $16 \%$ & $19 \%$ \\
\hline & $1,61-1,70$ & $53 \%$ & $52 \%$ \\
\hline & $1,71-1,80$ & $21 \%$ & $24 \%$ \\
\hline & $1,81-1,90$ & $5 \%$ & $*$ \\
\hline \multirow{5}{*}{ Peso } & $50-60$ & $11 \%$ & $5 \%$ \\
\hline & $61-70$ & $21 \%$ & $5 \%$ \\
\hline & $71-80$ & $21 \%$ & $48 \%$ \\
\hline & $81-90$ & $32 \%$ & $13 \%$ \\
\hline & $91-100$ & $15 \%$ & $29 \%$ \\
\hline
\end{tabular}

Legenda: * - Não obteve nenhuma resposta nesse item.

O perfil dos entrevistados revela que a maioria dos participantes pertence ao sexo feminino, tanto para Petrolina (58\%) como para Serra Talhada (76\%). A faixa etária predominante foi a de 21 a 30 anos em ambos os municípios. A maioria dos participantes das duas cidades apresenta faixa de altura predominante entre 1,61 m a 1,70 m. Em relação ao peso dos entrevistados, a faixa predominante foi 81-90 kg e 61-70 kg para Petrolina e Serra Talhada, respectivamente.

Tabela 3: Conhecimento dos participantes acerca do conceito de conforto térmico.

\begin{tabular}{lll}
\hline Rótulos de Linha & Petrolina & Serra Talhada \\
\hline Sim & $89,5 \%$ & $76 \%$ \\
Não & $10,5 \%$ & $24 \%$ \\
\hline
\end{tabular}

Com relação ao conhecimento sobre o conforto térmico, observou-se que $82,5 \%$ dos participantes, sendo $89,5 \%$ de Petrolina e $76 \%$ de Serra Talhada, afirmaram saber o que é conforto térmico (Tabela 3). Esse resultado corroborou com o do questionamento 'O que é conforto térmico?', no qual a maioria de ambos os municípios, afirmou que se trata de 'Uma sensação de bem-estar físico com as condições de temperatura da minha cidade' (Tabela 4).

Tabela 4: Nível de conhecimento dos participantes do conceito de conforto térmico.

\begin{tabular}{lll}
\hline Rótulos de Linha & Petrolina & Serra Talhada \\
\hline Se adaptar ao ambiente & $5 \%$ & $*$ \\
Se sentir confortável. & $5 \%$ & $5 \%$ \\
Uma sensação de bem-estar físico com as condições de temperatura da minha cidade. & $90 \%$ & $95 \%$ \\
\hline
\end{tabular}

Legenda: * - Não obteve nenhuma resposta nesse item. 
Desenvolver ações de Educação Ambiental para os moradores se mostra como uma opção viável, visto que, há congruência entre o conhecimento dos moradores e o conceito de conforto térmico. Logo, é possível afirmar que a temática tem relevância para a população dessas cidades e isso indica que há espaço para firmar um diálogo.

O questionário também abordou sobre apoio dos moradores ao emprego de práticas de Educação Ambiental com enfoque para qualidade térmica na cidade. O resultado apontou que quase a totalidade $(95 \%$ em Petrolina e $100 \%$ Serra Talhada) dos entrevistados, apoia e considera importantes ações voltadas para esta temática (Tabela 5).

Tabela 5: Apoio dos participantes ao emprego de práticas de Educação Ambiental com enfoque para qualidade térmica urbana.

\begin{tabular}{lll}
\hline Rótulos de Linha & Petrolina & Serra Talhada \\
\hline Sim & $95 \%$ & $100 \%$ \\
Não & $5 \%$ & $*$ \\
\hline
\end{tabular}

Legenda: * - Não obteve nenhuma resposta nesse item.

O papel da Educação Ambiental no bojo do entendimento da melhoria da qualidade de vida, deve considerar uma abordagem holística para que os indivíduos a partir de uma consciência coletiva respeitem o princípio da proteção ambiental (BRAGA et al., 2012). De acordo com a Lei no 9795/1999, que dispõe sobre a educação ambiental e a Política Nacional de Educação Ambiental, todos têm direito à educação ambiental, sendo de competência do Poder Público promover essa disciplina em todos os níveis de ensino. Além disso, deve ser estimulado o engajamento da sociedade na conservação, recuperação e melhoria do meio ambiente, com abordagem de problemáticas de escala local a global (BRASIL, 1999).

Para o estudo de conforto térmico é importante verificar o horário de preenchimento do questionário, pois o turno influencia na sensação térmica por causa da variação de temperatura ao longo do dia. Baseados nisso, os participantes foram questionados quanto ao turno em que se encontravam naquele momento de preenchimento. Em Petrolina 90\% respondeu o questionário no turno da noite e, em Serra talhada, 71\% pela manhã (Tabela 6).

Tabela 6: Horário de preenchimento do questionário.

\begin{tabular}{llll}
\hline Rótulos de Linha & Horário & Petrolina & Serra Talhada \\
\hline Manhã & $9: 00-14: 59 \mathrm{~h}$ & $5 \%$ & $71 \%$ \\
Tarde & $15: 00-20: 59 \mathrm{~h}$ & $5 \%$ & $5 \%$ \\
Noite & $21: 00-2: 59 \mathrm{~h}$ & $90 \%$ & $24 \%$ \\
\hline
\end{tabular}

Com obtenção dos dados acerca do horário de preenchimento dos participantes, foi possível sistematizar e identificar a percepção da sensação térmica relatada de acordo com o turno e município (Tabela 7). Verificouse que a grande parte das repostas (79\%) foi em relação à sensação térmica de 'com muito calor' em Petrolina, a concentração dessa mesma resposta também ocorreu para Serra Talhada (47,5\%). Já no caso do turno de ocorrência, essa sensação foi maior durante a manhã (38\%) em Serra Talhada, e em Petrolina nos turnos tarde e noite (ambos com 37\%).

Azevedo et al. (2017) em estudo sobre conforto térmico em Petrolina afirma que a área urbana do município sofre alterações nos parâmetros meteorológicos ao longo do dia, principalmente no turno da noite. Isso 
acarreta num quadro de desconforto térmico e corrobora com o presente estudo que apresenta grande parte das respostas da sensação de 'muito calor' nesse turno.

Tabela 7: Percepção da sensação térmica dos participantes no momento do preenchimento do questionário.

\begin{tabular}{|c|c|c|c|c|c|c|c|}
\hline \multirow{3}{*}{ Turno } & \multicolumn{7}{|c|}{ Sensação Térmica } \\
\hline & \multicolumn{2}{|l|}{ Com calor } & \multicolumn{2}{|c|}{ Com muito calor } & \multicolumn{2}{|c|}{ Levemente com calor } & \multirow{2}{*}{\begin{tabular}{|l|} 
Neutro \\
Serra Talhada
\end{tabular}} \\
\hline & Petrolina & Serra Talhada & Petrolina & Serra Talhada & Petrolina & Serra Talhada & \\
\hline Manhã & $*$ & $19 \%$ & $5 \%$ & $38 \%$ & $*$ & $4,8 \%$ & $9,5 \%$ \\
\hline Tarde & $5 \%$ & $9,5 \%$ & $37 \%$ & $9,5 \%$ & $*$ & $4,8 \%$ & $*$ \\
\hline Noite & $5 \%$ & $*$ & $37 \%$ & $*$ & $10 \%$ & $4,8 \%$ & $*$ \\
\hline TOTAL & $10 \%$ & $28,5 \%$ & $79 \%$ & $47,5 \%$ & $10 \%$ & $14,4 \%$ & $9,5 \%$ \\
\hline
\end{tabular}

Legenda: * - Não obteve nenhuma resposta nesse item.

Em decorrência desse quadro de percepção da sensação térmica, o grau de conforto alegado pelos participantes como sendo 'desconfortável' também se concentrou no período da tarde e noite para Petrolina e no período da manhã para Serra Talhada (Tabela 8). Chaves et al. (2015) relatam que a percepção nem sempre é compartilhada entre os indivíduos, embora haja quase sempre um consenso coletivo.

Tabela 8: Percepção de conforto térmico dos participantes no momento do preenchimento do questionário.

\begin{tabular}{lllll}
\hline Petrolina & & & & \\
\hline Turno & Confortável & Desconfortável & Levemente inconfortável & Muito inconfortável \\
Manhã & $*$ & $5,25 \%$ & $*$ & $21 \%$ \\
Tarde & $*$ & $10,5 \%$ & $21 \%$ & $10,5 \%$ \\
Noite & $5,25 \%$ & $16 \%$ & & $\%$ \\
\hline \multicolumn{2}{l}{ Serra Talhada } & & Levemente inconfortável & Muito inconfortável \\
\hline Turno & Confortável & Desconfortável & $19 \%$ & $14 \%$ \\
Manhã & $14 \%$ & $24 \%$ & $4,88 \%$ & $4,88 \%$ \\
Tarde & $4,88 \%$ & $9,5 \%$ & $4,88 \%$ & $*$ \\
Noite & $*$ & $*$ & & \\
\hline
\end{tabular}

Legenda: * - Não obteve nenhuma resposta nesse item.

Bem como, a maioria dos moradores de ambos os municípios, ao serem questionados acerca de sua satisfação para com a sensação térmica, afirmaram que preferiam estar se sentindo 'bem mais refrescado' (Tabela 9). Também se buscou investigar as alternativas que são utilizadas para amenizar a sensação individual de calor, no qual o entrevistado poderia marcar mais de uma opção. Conforme Tabela 10, a alternativa de utilização de roupas mais leves para chegar ao conforto térmico é a mais citada pelos participantes de Petrolina (42\%), e no caso de Serra Talhada o uso de ventilador (38\%).

Tabela 9: Satisfação dos participantes com a sensação térmica no momento do preenchimento do questionário.

\begin{tabular}{lll}
\hline Rótulos de Linha & Petrolina & Serra Talhada \\
\hline Assim mesmo & $*$ & $14 \%$ \\
Bem mais refrescado & $80 \%$ & $43 \%$ \\
Mais refrescado & $16 \%$ & $24 \%$ \\
Um pouco mais refrescado & $4 \%$ & $19 \%$ \\
\hline
\end{tabular}

Legenda: * - Não obteve nenhuma resposta nesse item.

Tabela 10: Medidas utilizadas pelos participantes para amenização da sensação individual de calor.

\begin{tabular}{lll}
\hline Rótulos de Linha & Petrolina & Serra Talhada \\
\hline Uso de roupas leves & $42 \%$ & $19 \%$ \\
Uso de aparelho de ar-condicionado & $32 \%$ & $33 \%$ \\
Uso de sombreamento & $*$ & $10 \%$ \\
\hline
\end{tabular}

Legenda: * - Não obteve nenhuma resposta nesse item.

Cândido et al. (2010) definem essa medida com adaptativa para situação de desconforto térmico em 
climas quentes, no qual movimento do ar se torna uma brisa agradável. Dessa forma, o uso de ventilação relatado pelos moradores do semiárido é uma opção de adaptação às condições térmicas, que ameniza o calor, mas gera um aumento do custo econômico e ambiental devido à necessidade de energia elétrica.

Os resultados dos índices de desconforto obtidos nas datas de aplicação dos questionários indicam um quadro de 'crescente de desconforto' em Petrolina (Tabela 10), ainda que a maioria de sua população alegasse 'levemente inconfortável'. Silveira et al. (2016) esclarecem que a temperatura de uma cidade é influenciada pelas diferenças no uso e ocupação do solo, visto que os materiais possuem propriedades diferentes, o que traduz a geração de campos térmicos locais diferenciados.

Tabela 10: Parâmetros meteorológicos, Índice de desconforto térmico de Thom (IDT) e respectiva classificação, nos diferentes turnos em pesquisa de conforto térmico na cidade de Petrolina, 2016.

\begin{tabular}{|c|c|c|c|c|c|}
\hline & Turno & $\mathbf{T}(\mathrm{o} C)$ & UR & IDT & Classes do Desconforto Térmico (IDT) \\
\hline \multirow{3}{*}{ 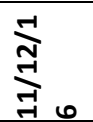 } & Manhã & 27,8 & 53,0 & 24,4 & Ligeiro desconfortável \\
\hline & Tarde & 33,6 & 34,0 & 26,6 & Crescente Desconforto \\
\hline & Noite & 35,0 & 27,0 & 26,8 & Crescente Desconforto \\
\hline \multirow{3}{*}{ 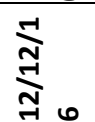 } & Manhã & 29,2 & 48,3 & 25,0 & Crescente Desconforto \\
\hline & Tarde & 35,4 & 28,5 & 27,2 & Relativo desconforto \\
\hline & Noite & 36,1 & 24,2 & 27,1 & Relativo desconforto \\
\hline \multirow{3}{*}{ 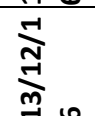 } & Manhã & 28,3 & 50,9 & 24,6 & Ligeiro desconforto \\
\hline & Tarde & 29,7 & 51,8 & 25,7 & Crescente desconforto \\
\hline & Noite & 26,4 & 69,4 & 24,4 & Ligeiro desconforto \\
\hline
\end{tabular}

No caso de Serra Talhada os resultados indicam que há predominância de um 'ligeiro desconforto térmico' (Tabela 10), que também contrariou os resultados da percepção com maioria para condição 'inconfortável'. Entretanto, Lundgren et al. (2014) em estudo sobre evidenciam que no município de Serra Talhada - PE o clima é de altas temperaturas e com insolação intensa, passando a ser um problema de saúde pública. No estudo realizado na cidade, Lundgren et al. (2013) tiveram como resultado o baixo número de árvores na cidade, observando também que as áreas calçadas que não recebem cobertura vegetal são bem maiores que as áreas cobertas.

Tabela 10: Parâmetros meteorológicos, Índice de desconforto térmico de Thom (IDT) e respectiva classificação, nos diferentes turnos em pesquisa de conforto térmico na cidade de Serra Talhada, 2016.

\begin{tabular}{|c|c|c|c|c|c|}
\hline & & $\mathrm{T}(\mathrm{o} C)$ & UR & IDT & Classificação de Desconforto Térmico (IDT) \\
\hline \multirow{3}{*}{$\underset{\exists}{\stackrel{I}{I}} 0$} & Manhã & 25,8 & 57,3 & 23,2 & Ligeiro desconforto \\
\hline & Tarde & 32,3 & 32,7 & 25,7 & Crescente desconforto \\
\hline & Noite & 33,2 & 42,0 & 27,2 & Relativo desconforto \\
\hline \multirow{3}{*}{ 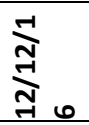 } & Manhã & 25,4 & 57,3 & 22,8 & Ligeiro desconforto \\
\hline & Tarde & 32,9 & 30,1 & 25,8 & Crescente desconforto \\
\hline & Noite & 33,2 & 27,8 & 25,8 & Crescente desconforto \\
\hline \multirow{3}{*}{ 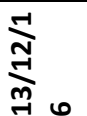 } & Manhã & 25,7 & 55,3 & 22,9 & Ligeiro desconforto \\
\hline & Tarde & 32,6 & 28,3 & 25,4 & Crescente desconforto \\
\hline & Noite & 32,5 & 26,2 & 25,2 & Crescente desconforto \\
\hline
\end{tabular}

Em áreas naturais há predisposição de temperaturas mais amenas em comparação às áreas urbanizadas (SILVEIRA et al., 2016), este fator se deve ao fato da regulação realizada pela vegetação, de modo a atuar como barreira à radiação solar direta, promovendo a diminuição de disponibilidade de energia para aquecer o ar (MENDONÇA et al., 2010). Esse fator é confirmado no estudo de Silveira et al. (2016), onde concluíram que a área arborizada apresentou os menores índices de temperatura e maiores de umidade relativa do ar, diferentemente na área urbanizada, onde apresentou maior temperatura. Os autores supracitados constataram também a 
importância do conforto térmico para atração de turistas, e afirmam que as condições consideradas confortáveis são serviços ambientais prestados pelo ecossistema.

Gomes et al. (2003) deixam claro que a arborização pode contribuir significativamente na amenização do clima urbano e, principalmente, para a melhoria da qualidade de vida humana, mas o crescimento das cidades de forma contínua e desordenada tem ocasionado diminuição de árvores e influência notável no microclima urbano.

A Educação ambiental como prática de engajamento da população do Semiárido na gestão de recursos hídricos já é reconhecida como um importante processo emancipatório (SANTOS et al., 2018). Entretanto, a participação popular perante o planejamento urbano dos municípios do semiárido ainda carece de estudos tendo em vista sua baixa ocorrência (GOMES et al., 2019). Com a participação das comunidades é possível construir estratégias que assegurem o conforto térmico urbano, e outros parâmetros de qualidade ambiental. Essas estratégias envolvem o zoneamento da malha urbana, arborização adequada e diminuição de gases do efeito estufa (BARROS et al., 2018; LIMA et al., 2018).

Ventura et al. (2011), aplicando a Policultura em uma região do Semiárido do Estado da Bahia, demonstraram que o emprego de tecnologia simplificada e própria do conhecimento popular foi satisfatória para contribuir no Desenvolvimento Humano (DH) nas comunidades estudadas. O ponto de partida do estudo constituiu-se de novas formas de adaptação à realidade climática, com menor emissão de gases do efeito estufa e convivência com o semiárido. A educação ambiental é capaz de compreender a influência das ações locais numa perspectiva global, e considera a indispensabilidade de haver preservação, mas que somente se concretiza por meio do conhecimento, sapiência, integração e, principalmente, do respeito pela natureza que nos cerca (LACERDA et al., 2010). Ojima (2013) destaca que medidas de adaptação mediante de tais mudanças globais devem ser capazes de considerar os desafios em cenários futuros, somente assim será possível garantir justiça socioambiental. Portanto, é urgente e necessária a implementação de práticas de Educação ambiental para população visando sustentabilidade dos ecossistemas do Semiárido (CAVALCANTI et al., 2005).

\section{CONCLUSÕES}

A partir do desenvolvimento de análise acerca da percepção de população do Semiárido pernambucano em relação ao conforto térmico, foi possível verificar que a maioria tem conhecimento do respectivo conceito. Dentro do recorte geográfico do presente estudo, nota-se que a percepção de desconforto térmico é acentuada no município de Petrolina. Embora, os resultados expressos por meio do uso de índice bioclimático de desconforto, indiquem que a classificação de 'Crescente desconforto' ocorra em maior número ao longo dos dias de análise em Serra Talhada.

Os resultados preliminares obtidos por meio do uso de questionário estruturado em aspectos subjetivos do conforto térmico sugerem que há uma maior insatisfação com a situação térmica em Petrolina. Portanto, a percepção dos moradores das condições térmica do ambiente urbano desse município indica que há quase um consenso de que o presente quadro de conforto térmico provoca stress térmico e que desejam uma amenização da sensação térmica.

No caso de Serra Talhada os parâmetros meteorológicos apresentam um quadro de desconforto 
térmico ao longo dos dias no recorte temporal, entretanto, a população do município relata mais satisfação com o ambiente térmico. Porque na dentro da escala subjetiva sobre satisfação e medidas empregadas para amenização térmica, houve uma distribuição mais uniforme de respostas. Isso pode indicar uma adaptação térmica da população ao quadro de conforto térmico do município.

Nesse sentido, sugere-se que sejam desenvolvidos estudos sobre adaptação climática e resiliência ao stress térmico nessas cidades do Semiárido, que utilizem série histórica de parâmetros meteorológicos e múltiplos índices de conforto térmico (bioclimático, fisiológico, subjetivos, biofísico). Visando compreender a dinâmica microclimática e sua influência no conforto térmico, bem como investigar os limites de adaptação dos indivíduos submetidos a stress térmico.

Além disso, os dados demonstraram que, em ambos os municípios, os moradores apresentaram interesse por ações de Educação Ambiental com foco para o ambiente térmico. Visto que as condições térmicas afetam diretamente o desenvolvimento de atividades humanas, o enfoque climático nessa prática é um fator de relevância na sensibilização da população para práticas sustentáveis. De mesmo modo, podem ser empregadas como instrumento político de engajamento da população com as políticas públicas de planejamento do território urbano e de meio ambiente.

AGRADECIMENTOS: À Fundação de Amparo ACEPE pela concessão da bolsa de Pós-Graduação para os autores. À Universidade Federal Rural de Pernambuco - UFRPE, especialmente ao programa de Pós-Graduação em Engenharia Ambiental, e também ao Grupo de Pesquisa Centro de Inovação Tecnológica Aplicada aos Recursos Naturais CITAR/UFRPE.

\section{REFERÊNCIAS}

AZEVEDO, P. V.; BEZERRA, P. T. C.; LEITÃO, M. M. V. B. R.; SANTOS, C. A. C.. Thermal comfort level assessment in urban area of Petrolina-PE County, Brazil. Revista Brasileira de Meteorologia, v.32, n.4, p.555-563, 2017.

BARROS, A. P. S.; AZEVEDO, A. C. J.; DIAS, E. R. S.; OLIVEIRA, H. M. P.. Planejamento urbano, áreas verdes e qualidade de vida: Uma análise comparativa entre os bairros Terra Firme e Cidade Velha-Belém/PA. Revista Geoaraguaia, v.7, n.2, p.68-85, 2018.

BEZERRA, P. T. C.; RAMOS, M. M. V. B.; LEITÃO, P. V.. Ilhas de Calor e Desconforto Térmico no Semiárido Brasileiro: Um Estudo de Caso na cidade de Petrolina-PE. Revista Brasileira de Geografia Física, v.6, n.3, p.427-441, 2013.

BRAGA, R.; EL-DIER, S. G.. Educação Ambiental como tema para extensão rural. In: EL-DEIR, S. G.. Educação Ambiental no semiárido: proposta metodológica de extensão rural. Recife: EDUFRPE, 2012.

BRASIL. Lei n. 9.795, de 27 de abril de 1999. Dispõe sobre a educação ambiental, institui a Política Nacional de Educação Ambiental e dá outras providências. Brasília: DOU, 1999.

BRASILEIRO, R. S.. Alternativas de desenvolvimento sustentável no semiárido nordestino: da degradação à conservação. Scientia Plena, v.5, n.5, p.1-12, 2009.

CÂNDIDO, C.; LAMBERTS, R.; BITTENCOURT, L.; DEAR, R.. Aplicabilidade dos limites da velocidade do ar para efeito de conforto térmico em climas quentes e úmidos. Ambiente Construído, v.10, n.4, p.59-68, 2010.

CASTRO, F. C.; SANTOS, A. M.. Susceptibilidade ambiental a salinização das terras em municípios da microrregião de Petrolina, Pernambuco, Brasil. Caminhos da Geografia, v.16, n.56, p.160-172, 2015.

CAVALCANTI, E. R.; COUTINHO, S. F. S.; SELVA, V. S. F.; OLIVEIRA NETO, A.. Educação Ambiental como Instrumento de Gestão: a importância da formação de professores no processo de combate à desertificação no semiárido brasileiro. In: SIMPÓSIO BRASILEIRO DE RECURSOS HÍDRICOS, 16. ANAIS. São Paulo: ABRH, 2005. p.508-509.

CHAVES, A. M. S.; AMADOR, M. B. M.. Percepção Ambiental de frequentadores dos espaços livres públicos: um estudo no município de Correntes-PE. Caminhos de Geografia, v.16, n.53, p.118-132, 2015.

CPRM. Serviço Geológico do Brasil. Diagnóstico do município de Petrolina. Recife: CPRM. 2005a. 
CPRM. Serviço Geológico do Brasil. Diagnóstico do município de Serra Talhada. Recife: CPRM, 2005b.

FARIAS, M. P.. Índices de seca meteorológica para a microrregião de Petrolina, PE, e Juazeiro, BA. Monografia (Especialização em Geoambiência e Recursos Hídricos do Semiárido) - Universidade Estadual da Paraíba, Campina Grande, 2014.

GIL, A. C.. Métodos e Técnicas de Pesquisa Social. São Paulo: Atlas, 2008

GOMES, M. A. S.; SOARES B. R.. A vegetação nos centros urbanos: considerações sobre os espaços verdes em cidades médias brasileiras. Estudos Geográficos, v.1, n.1, p.19-29, 2003.

GOMES, Y. B.; CARACRISTI, I.. Clima urbano e Percepção térmica dos moradores das pequenas cidades do semiárido: uma análise da cidade de Forquilha. Revista Homem, Espaço e Tempo, v.13, n.2, p.67-81, 2019.

INSA. Instituto Nacional do Semiárido. Desertificação e mudanças climáticas no semiárido brasileiro. Campina Grande: INSA-PB, 2011.

INSA. Instituto Nacional do Semiárido. Semiárido Brasileiro. Campina Grande: INSA-PB, 2013.

ISO. International Organization for Standardization. ISO 10.551: ergonomics of the thermal environment: assessment of the influence of the thermal environment using subjective judgment scales. Genebra: ISO, 1995.

JATOBÁ, L.; SILVA, A. F.; GALVÍNCIO, J. D.. A dinâmica climática do Semiárido em Petrolina-PE. Revista Brasileira de Geografia Física, v.10, n.1, p.136-149, 2017.

LACERDA, N. P.; SOUTO, P. C.; DIAS, R. S.; SOUTO, R. S.; SOUTO, J. S.. Percepção dos residentes sobre a arborização da cidade de São José de Piranhas, PB. REVSBAU, v.5, n.4, p.81-95, 2010.

LEAL FILHO, W.; ICAZA, L. E.; NEHT, A.; KLAVINS, M.; MORGAN, E.. Coping with the impacts of urban heat islands. A literature based study on understanding urban heat vulnerability and the need for resilience in cities in a global climate change context. Journal of Cleaner Production, v.171, n.10, p.1140-1149, 2018.

LIMA, Y. E. S. P. D.; LIMA, M. D. L. S. P.; GOMES, E. G.. A educação ambiental por meio do incentivo da arborização visando ao conforto térmico no Município de Bayeux, Estado da Paraíba, Brasil. Revista Brasileira de Gestão Ambiental e Sustentabilidade, v.5, n.10, p.799-804, 2018.

LUNDGREN, W. J. C.; SILVA, L. F.; ALMEIDA, A. Q.. Influência das espécies exóticas arbóreas urbanas na área de cobertura da cidade de Serra Talhada, PE. REVSBAU, v.8, n.3, p.96-107, 2013.

LUNDGREN, W. J. C.; SILVA, L. F.; AMORIM, T. L.; SILVA, K. P. S.. Análise da temperatura do solo abaixo da copa de três espécies de árvores na Cidade de Serra Talhada, PE. REVSBAU, v.9, n.4, p.1-21, 2014.

MARENGO, J.; CUNHA, A.; ALVES, L.. A seca de 2012-15 no semiárido do Nordeste do Brasil no contexto histórico. Revista Climanálise, v.3, p.49-54, 2016.

MARTINI, A.; BIONDI, D.; BATISTA, A. C.; ZAMPRONI, K.; VIEZZER, J.; GRISE, M. M.; LIMA NETO, E. M.. Percepção da população sobre o conforto térmico proporcionado pela arborização de ruas de Curitiba - PR. Revista Floresta, v.44, n.3, p.515 $-524,2014$.

MEDEIROS, M. C. G.; NASCIMENTO, T. A.; SILVA JUNIOR, E. O. S.; AMORIM, A. C.; NÓBREGA, R. S.. Caracterização dos índices térmicos e pluviométricos no Semiárido Pernambucano: o caso do município de PetrolinaPernambuco-Brasil. In: WORKSHOP INTERNACIONAL SOBRE ÁGUA NO SEMIÁRIDO BRASILEIRO, 1. ANAIS. Campina Grande: UFCG, 2015.

MENDONÇA, F. A.; DANNI-OLIVEIRA, I. M.. Climatologia: noções básicas e climas do Brasil. Sociedade \& Natureza, v.22, n.3, p.639-640, 2010.

OJIMA, R.. Urbanização, dinâmica migratória e sustentabilidade no semiárido nordestino: o papel das cidades no processo de adaptação ambiental. Cadernos Metrópole, v.15, n.29, p.35-54, 2013.

OLIVEIRA, K. A.; CORONA, H. M. P.. A percepção ambiental como ferramenta de propostas educativas e de políticas ambientais. Revista Científica ANAP Brasil, v.1, n.1, p.53-72, 2011.

SANTOS, T. M. M.; OLIVEIRA, J. L. S.; SILVA, E.. Vulnerabilidade hídrica no Nordeste brasileiro: entre a urbanização e a Educação Ambiental. Revista Eletrônica do Mestrado em Educação Ambiental, v.35, n.3, p.184-199, 2018.

SHARIFI, E.; BOLAND, J.. Limits of thermal adaptation in cities: outdoor heat-activity dynamics in Sydney, Melbourne and Adelaide. Architectural Science Review, v.61, n.4, p.191-201, 2018.

SILVA, L. B.; SANTOS, F. A. R.; GASSON, P.; CUTLER, D.. Anatomia e densidade básica da madeira de CaesalpiniapyramidalisTul. (Fabaceae), espécie endêmica da caatinga do Nordeste do Brasil. Acta Bot. Bras., v.23, n.2, p.436-445, 2009.

SILVEIRA, I. M. M.; CARVALHO, R. G.. Microclima e conforto térmico na área da Mata da Bica, no município de Portalegre/RN. Revista Brasileira de Geografia Física, v.9, n.1, p.62-78, 2016.

SUDENE. Superintendência do Desenvolvimento do Nordeste. Resolução n. 115, de 23 de novembro de 2017. Dispõe sobre a nova delimitação do Semiárido brasileiro. Brasília: DOU, 2017.

TAVARES, V. C.; ARRUDA, I. R. P.; SILVA, D. G.. Desertificação, mudanças climáticas e secas no semiárido brasileiro: uma revisão bibliográfica. Geosul, v.34, n.70, p.385-405, 2019.

VENTURA, A. C.; ANDRADE, J. C. S.. Polyculture in the semiarid regions of Brazil. Field Actions Science Reports, n.3, 2011.

ZHOU, B.; RYBSKI, D.; KROPP, J.. The role of city size and 
urban form in the surface urban heat island. Nature

Scientific Reports, v.7, n.1, p.1-9, 2017

A CBPC - Companhia Brasileira de Produção Científica (CNPJ: 11.221.422/0001-03) detém os direitos materiais desta publicação. Os direitos referem-se à publicação do trabalho em qualquer parte do mundo, incluindo os direitos às renovaç̃oses, expansões e disseminações da contribuição, bem como outros direitos subsidiários. Todos os trabalhos publicados eletronicamente poderão posteriormente ser publicados em coletâneas impressas sob coordenação da Sustenere Publishing, da Companhia Brasileira de Produção Científica e seus parceiros autorizados. Os (as) autores (as) preservam os direitos autorais, mas não têm permissão para a publicação da contribuição em outro meio, impresso ou digital, em português ou em tradução. 